\title{
Response of naïve two-spotted gobies Gobiusculus flavescens to visual and chemical stimuli of their natural predator, cod Gadus morhua
}

\author{
Anne Christine Utne-Palm* \\ Department of Fisheries and Marine Biology, University of Bergen, PO Box 7800, Bergen 5020, Norway
}

\begin{abstract}
In order to determine whether the anti-predator response of gobies to cod Gadus morhua is inherited, naïve two-spotted gobies Gobiusculus flavescens were exposed to visual or chemical cod stimuli, in order to determine whether such stimuli would trigger an innate anti-predator response. Groups of 10 naïve adult two-spotted gobies were tested for their distribution between 2 habitats in an aquarium: 1 'safe' and 1 'risky' habitat, in which a cod was presented either visually or by its odour. Equal amounts of food were available in the 2 habitats. When no predator stimuli were presented in either habitat, the gobies distributed themselves equally between them both. When a visual stimulus of a cod was presented in 1 of the habitats, they avoided this habitat. The introduction of cod odour in 1 of the habitats did not influence the distribution of the gobies. After a single session with a cod physically present in 1 habitat, the gobies still did not respond to the introduction of cod odour the following day. However, after having experienced a cod being physically present on 3 consecutive feeding sessions, they responded to cod odour with avoidance. The response to cod odour was still significant 6 mo after the experience. It therefore appears that the goby has an innate fear of any larger fish, while the recognition of a specific predator odour has to be learned.
\end{abstract}

KEY WORDS: Innate response · Olfactory predator cue · Visual predator cue · Gobiusculus flavescens - Gadus morhua

\section{INTRODUCTION}

If fish that have been raised without exposure to predators (or to other cues that could be involved in the development of an anti-predator response) exhibit the predator-evasive behaviour seen in wild populations then there is good reason to believe that such behaviour is inherited (Magurran 1990). A recent study (Hirvonen et al. 2000) has demonstrated that young Arctic char Salvelinus alpinus, which were completely naïve regarding piscivores, could distinguish between different taxa of predators as well as the different taxa com-

*E-mail: anne.utne@ifm.uib.no prising their own diets on the basis of chemical cues alone. This suggests that the anti-predator behaviour is controlled by genetic factors. The response was explained by these authors in terms of the long coevolutionary history of these species. In a study of fathead minnows Pimphales promelas, Chivers \& Smith (1994) found that naïve minnows did not respond to chemical stimuli from northern pike Esox lucius, while wildcaught minnows did. However, naïve minnows that were exposed simultaneously to chemical stimuli from pike and minnow alarm substance exhibited a fright response on subsequent exposure to the chemical pike stimulus alone. This indicated that anti-predator behaviour can be modified by experience, in this case as a releaser-induced recognition learning process (see 
Suboski 1990). Many studies have shown that fish can inherit anti-predator behaviour (e.g. Zebra danios Brachydanio rerio, Dill 1974; three-spined stickleback, Gasterosteus aculeatus, Giles 1984; paradise fish Macropodus opercularis Csányi 1985; European minnow Poxinus poxinus Magurran 1990), and that their behaviour is modified by experience of predators (Dill 1974, Magurran 1990, Csányi \& Dóka 1993). Studies of the effects of chemical cues from predators on prey fish have so far been performed on freshwater species, with a few exceptions (Pfeiffer 1977, Smith 1989, Utne \& Bacchi 1997), and studies on naïve individuals have looked only at freshwater species.

An earlier study of wild-caught two-spotted gobies (Utne \& Bacchi 1997) showed that if chemical and/or visual stimuli from a predator cod Gadus morhua were presented together with the food at a feeding site, the gobies would avoid that site. The avoidance persisted during feeding sessions for 1 or $2 \mathrm{~d}$ after exposure. Cod are the most common predators on two-spotted gobies (Nordeide \& Salvanes 1991). Two-spotted gobies and 0 -group coastal cod share the same habitat, the kelp area of the littoral zone, and we might therefore expect to find an innate anti-predator response in gobies. In this study, naïve two-spotted gobies were exposed to either visual or chemical cues from a cod in order to determine whether such stimuli would trigger an inherited anti-predator response. The results are compared with earlier studies of anti-predator responses in wild two-spotted gobies (Utne et al. 1993, Utne \& Bacchi 1997).

\section{MATERIALS AND METHODS}

The 'Ideal Free Distribution' measure. The influence of the 2 predator stimuli-image and odour-on habitat choice and feeding behaviour of the gobies was quantified by studying the deviation from an 'Ideal Free Distribution' (IFD, Fretwell \& Lucas 1970). It has been demonstrated earlier (Utne et al. 1993, Utne \& Bacchi 1997) that like several other fish species (Milinski 1979, Gillis \& Kramer 1987, Pitcher et al. 1988), wild two-spotted goby distribute themselves according to the IFD in the presence of a resource. When individuals of a group are distributed according to the IFD in the presence of a resource, in this case food, it is possible to investigate the influence of other factors (e.g. predation risk) by measuring the deviation from the IFD when individuals are exposed to such factors (Abrahams \& Dill 1989). Previous studies utilising this approach have shown that wild two-spotted goby avoid a feeding patch containing a cod (Utne et al. 1993, Utne \& Aksnes 1994) or cod stimuli (odour and/or visual image) (Utne \& Bacchi 1997), and feed in a safe patch. This study took the same approach (deviation from IFD), in order to clarify whether cod odour or cod image have short- and/or long-term effects on the feeding behaviour or choice of habitat of naïve twospotted gobies.

Fish history. The gobies were captivity-reared, firstgeneration offspring of 43 and 27 wild-caught female and male gobies, which were collected with a beach seine in April-May 1999 over a hard-bottom habitat covered with Fucus spp. (Raunefjorden, nr Bergen, western Norway). Eggs were spawned between 22 April and 26 June 1999. The eggs hatched after about $18 \mathrm{~d}$ of tending by the male gobies (for further details see Skolbekken \& Utne-Palm 2001). Larvae were fed algae and rotifers until $40 \mathrm{~d}$ post hatching (ph), when Artemia were introduced. After $80 \mathrm{~d}$ ph, pellets $(<600 \mu \mathrm{m}$, Aglonorse No. 1, Norsildmel Trading A/S, Norway) were introduced to the larvae, and after $100 \mathrm{~d}$ ph this was the only source of food. A temperature of $9 \pm 1^{\circ} \mathrm{C}$ was maintained throughout the rearing and experimental periods. Larvae were kept in small, circular $80 \mathrm{l}$ tanks until $30 \mathrm{~d}$ ph, when they were transferred to $500 \mathrm{l}$ tanks. Before $80 \mathrm{~d}$ ph there was no flowthrough system in the holding tanks, in order to avoid the larvae being drained off, but the water was aerated continuously and the floors of the tanks were siphoned clean of waste food and faeces every day. At an age of 10/11 mo (in April 2000) the gobies were tested for their anti-predator response.

Experimental procedure. Groups of 10 gobies were transferred to 6 experimental aquaria $(0.8 \times 0.4 \times 0.2 \mathrm{~m})$. Only male gobies of equal size (ca $35-40 \mathrm{~mm}$ ) were used in the experiments, as risk taking in Gobiusculus flavescens has been found to be sex related (Utne 1995). The gobies were habituated to the aquaria for $7 \mathrm{~d}$ before the experiments and were fed live copepods daily. No food was given in the $24 \mathrm{~h}$ before the experiments. Water flowed through the aquaria at all times except during the trials. The aquaria were divided in 2 equal parts by a net, with a feeding site on each side of the net. The experimental area in each aquarium was $0.32 \mathrm{~m}^{2}$.

Zooplankton (mainly consisting of copepods), which were used as prey, were collected with plankton nets and kept alive in containers at low temperature (6 to $8^{\circ} \mathrm{C}$ ) for a maximum of $3 \mathrm{~d}$. During the experimental period (20 $\mathrm{min})$, zooplankton $(0.5$ to $2 \mathrm{~mm}$ ) were supplied in suspension through 2 seawater inlets on opposite sides of the aquarium. Each side was supplied with 1.51 of zooplankton suspension during the experimental period. This design was previously used by Utne et al. (1993), Utne \& Aksnes (1994) and Utne \& Bacchi (1997). The plankton species composition was the same in both sides of the aquarium within but not among experiments (due to the use of natural plankton). Openings in the nets that divided the aquaria in 2 
equal parts were small enough to limit the cod to 1 side, while the gobies could pass through them freely. The nets also delayed the mixing/diffusion of the 2 zooplankton suspensions (see Utne \& Bacchi 1997).

The distribution of the gobies between the 2 sites was recorded on video tape. A 12:12 h light cycle with dusk and dawn simulation was used. The experiments were always initiated at midday, when the light was at a maximum of around $60 \mu \mathrm{mol} \mathrm{m} \mathrm{m}^{-2} \mathrm{~s}^{-1}$.

Experiments with predator. A single 0-group $(20 \mathrm{~cm})$ wild cod Gadus morhua was used as a predator stimuli. Before the experiment and between trials the cod was kept in a fish tank $(1 \times 1 \times 0.9 \mathrm{~m})$ together with other wild cod of similar size, where they were fed daily with dead Gobiusculus flavescans, which was bycatch from field samplings using a beach seine.

In order to create a zooplankton suspension saturated with cod odour, the cod was moved from the main cod tank to a separate 301 holding tank, where it was kept for $24 \mathrm{~h}$. Here the water was kept aerated but was not changed and the cod was not fed. One of the 2 zooplankton suspensions was made by suspending plankton in water from this tank instead of the experimental aquarium.

During the trials when the effects of visual stimuli were tested, the cod was placed in a transparent glass container adjacent to 1 of the feeding sites. Before the cod was visually introduced, 5 experiments were carried out with an empty glass container, in order to check whether the container had any influence on the distribution of the gobies.

Trials in which no response to odour occurred were followed by a second trial, during which the cod was physically introduced into 1 of the feeding sites for a 20 min session. During this time the gobies had to evade attacks from the cod, a process hereafter called cod-conditioning. On the day following the cod-conditioning trial the gobies were again tested for their response to cod odour. This procedure was repeated until an anti-predator response to cod odour was observed. Both naïve and experienced (cod-conditioned) gobies were re-tested for their response to predator odour after 6 mo (October 2000).

Inspection activity by the gobies was analysed in the experimental set-ups with a cod visual stimulus (i.e. cod present and cod in glass container). Inspection was defined as by Pitcher et al. (1986).

Ethics. The experimental procedures were approved by the 'Norwegian Council for Animal Research', which supervises EU animal experimentation regulations in Norway. The gobies had a refuge in the safe side of the aquarium, where the predator could not reach them. The 2 halves of the aquarium were small $\left(0.16 \mathrm{~m}^{2}\right)$, which made it difficult for the cod to attack successfully (fast-start performance which requires space), while giving the gobies a short distance to safety. The cod chased the gobies, but no gobies were ever caught by the cod, as they all escaped through the net to the safe side of the aquarium.

Statistical methods. The food ratio of 1:1 was used in order to see whether the gobies distributed themselves according to the food, in the absence or presence of predator, predator odour or image. The number of fish in each half of the aquarium was recorded every $30 \mathrm{~s}$ during the $20 \mathrm{~min}$ trials. The recording started $90 \mathrm{~s}$ after the start of feeding, as the gobies needed some time to explore the relative profitability of the 2 feeding sites (Utne et al. 1993). The mean number of fish at each feeding site during the $37 \mathrm{ob}$ servations was used to characterise the distribution in each trial. Mean and standard deviations were calculated on the basis of the 5 replicates. The Ideal Free Distribution (food only) trials and those that employed a second stimulus (glass container, visual stimulus, cod odour or actual cod present) were compared by 2-way ANOVA for repeated measurements. The raw data (mean number of fish at the affected site) were log-transformed in order to obtain a normal distribution. The differences between the different experimental set-ups (IFD, odour-naïve, odour-experienced, cod image and cod present) were also tested by 2-way ANOVA for repeated measurements, with a Newman-Keults post hoc test. The proportion of studies with inspection events (inspection rate) and the number of inspection events were recorded for the studies in which a cod was present, either visually or physically. Gobies that were inactive, lying on the bottom or in the corners of the aquarium during the experiments, were excluded from the analysis, as they were not actively feeding. Consequently, the results are sometimes based on less than 10 fish. A trial was eliminated if more than 2 fish were inactive during the whole period.

\section{RESULTS}

When food alone was introduced into the 2 feeding sites in equal amounts, the 10 naïve gobies distributed themselves according to food availability (Ideal Free Distribution), with ca 5 fish at each site (Fig. 1). The introduction of a glass container had no influence on the distribution (Table 1).

\section{Experiments with predator stimuli on naïve gobies}

When a cod was present in a glass container (i.e. visual stimulus) at 1 of the feeding sites, there was a significant avoidance of that side of the aquaria 


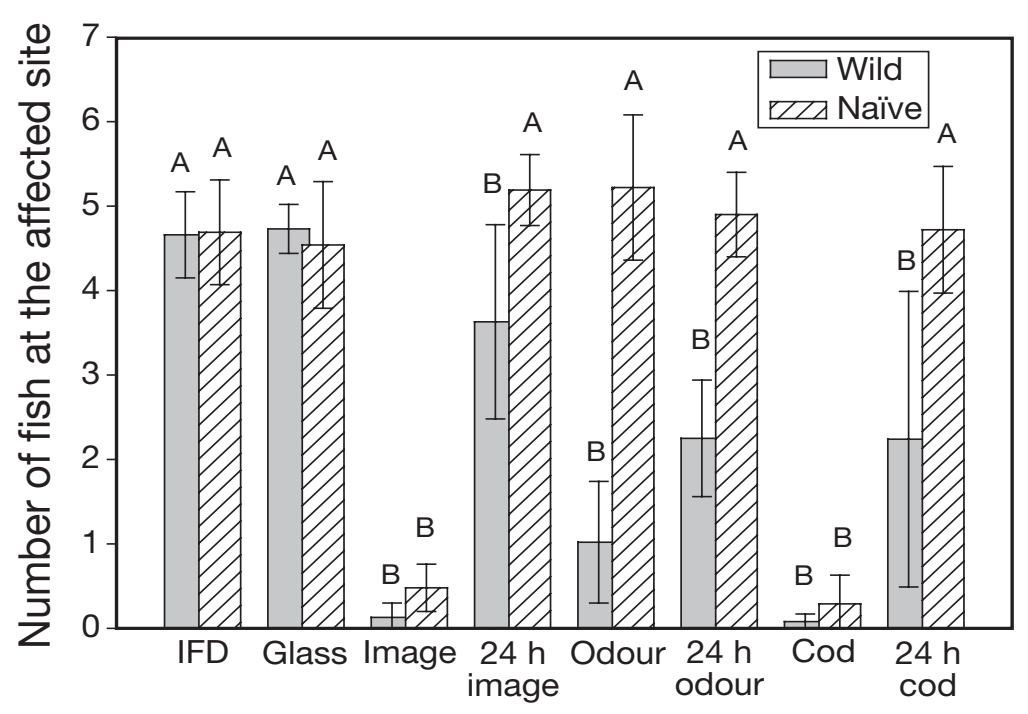

Fig. 1. Anti-predator response of wild and naïve Gobiusculus flavescens. Average number of wild gobies (Utne et al. 1993, Utne \& Bacchi 1997) and naïve gobies on stimulus-affected side of aquarium at the time of stimulus introduction and $24 \mathrm{~h}$ later. Standard errors indicated. Significant relationships between treatments indicated (A \& B) on top of bar. IFD: Ideal Free Distribution, when only food presented; Glass: mean number of fish (mnf) at side of aquarium adjacent to glass container; Image: mnf at side where predator presented visually; Odour: mnf at side where predator odour presented; Cod: mnf at side where predator physically present; $24 \mathrm{~h}$ image, -odour or -cod: mnf at affected side $24 \mathrm{~h}$ after stimulus presented

(Table 1, Fig. 1, naïve). However, there was no avoidance of the affected site $24 \mathrm{~h}$ after the introduction of the visual stimulus (Fig. 1, naïve). The introduction of cod odour had no significant effect on distribution (Table 1). The physical presence of a cod in 1 of the feeding sites produced a significant avoidance response at the time (Table 1, Fig. 1, naïve), but there was no avoidance of the affected site $24 \mathrm{~h}$ later (Fig. 1, naïve). When these results are compared with earlier results from wild two-spotted gobies, the visual image had a significantly lower avoidance effect on the naïve gobies than on the wild gobies (ANOVA, $F_{1,11}=6.9, \mathrm{p}=$ 0.02) (Utne \& Bacchi 1997), while the presence of a cod had similar effect on wild and naïve gobies (ANOVA, $F_{1,11}=$ 2.4, $\mathrm{p}=0.15$ ) (Utne et al. 1993) (Fig. 1).

\section{Learning predator odour}

The naïve gobies did not respond to cod odour alone (Table 1). After the first 20 min experience of the physical presence of a cod in 1 of the feeding present. sites, they still did not respond to cod odour the next day (Table 2, Fig. 2). There was a limited response after the second cod-conditioning treatment (some of the groups responded), as can be seen by the significant effect of fish group and the almost significant interaction effect $(\mathrm{p}=0.072)$ (Table 2, Fig. 2). After the third cod-conditioning treatment the gobies responded significantly to cod odour the following day (Table 2, Fig. 2). Six mo after the first conditioning treatment, cod-conditioned gobies still responded significantly to cod odour. However, response was significantly lower than it had been 6 mo earlier (Table 3). The naïve unconditioned gobies still did not respond to cod odour 6 mo later (Fig. 2).

\section{Inspection}

An inspection rate of 0.8 was found for the visual stimulus study, compared to 0.2 in the study where a cod was present in the aquarium. There were a further 12 inspection events during the visual stimulus studies and 3 in the studies in which a cod was

Table 1. Two-way ANOVA for repeated measurements, expressing significance level (p) of differences in distribution pattern of the fish without predator stimuli (Ideal Free Distribution) compared to with predator stimuli (cod image, cod odour or cod physically present) with respect to fish group (replicate group of 10 gobies). Effect of glass container also presented

\begin{tabular}{|lrrrc|}
\hline Effect & df effect & df error & $F$ & $\mathrm{p}$ \\
\hline Cod image & & & & \\
Fish group & 2 & 2 & 3.26 & 0.235 \\
Image stimuli & 1 & 2 & 269.73 & $0.004^{*}$ \\
Fish group and visual stimuli & 2 & 2 & 0.85 & 0.541 \\
Cod odour & & & & \\
Fish group & 2 & 2 & 0.53 & 0.653 \\
Cod odour & 1 & 2 & 2.20 & 0.276 \\
Fish group and cod odour & 2 & 2 & 1.87 & 0.349 \\
Cod present & & & & \\
Fish group & 2 & 2 & 0.40 & 0.714 \\
Cod present & 1 & 2 & 1863.27 & $0.0005^{*}$ \\
Fish group and cod present & 2 & 2 & 3.54 & 0.220 \\
Glass container & & & & \\
Fish group & 2 & 2 & 2.45 & 0.289 \\
Glass container & 1 & 2 & 0.65 & 0.504 \\
Fish group and glass container & 2 & 2 & 1.16 & 0.464 \\
* Significant difference & & & & \\
\hline
\end{tabular}


Table 2. Two-way ANOVA for repeated measurements, expressing significance level $(p)$ of differences in the distribution pattern of the fish without predator stimuli (Ideal Free Distribution), compared to when predator odour was presented after the fish had experienced a cod being physically present $(1,2$ or 3 times, for $20 \mathrm{~min}$ ), and response to cod odour 6 mo after 3 exposures

\begin{tabular}{|c|c|c|c|c|}
\hline Effect & df effect & df error & $F$ & $\mathrm{p}$ \\
\hline \multicolumn{5}{|l|}{ Experienced cod once } \\
\hline Fish group & 2 & 2 & 0.90 & 0.527 \\
\hline Odour & 1 & 2 & 0.11 & 0.768 \\
\hline Fish group and odour & 2 & 2 & 4.28 & 0.189 \\
\hline \multicolumn{5}{|l|}{ Experienced cod twice } \\
\hline Fish group & 2 & 2 & 171.86 & $0.006^{*}$ \\
\hline Odour & 1 & 2 & 0.50 & 0.554 \\
\hline Fish group and odour & 2 & 2 & 12.97 & 0.072 \\
\hline \multicolumn{5}{|l|}{ Experienced cod 3 times } \\
\hline Fish group & 2 & 2 & 1.19 & 0.838 \\
\hline Odour & 1 & 2 & 22.05 & $0.0425^{*}$ \\
\hline Fish group and odour & 2 & 2 & 0.26 & 0.791 \\
\hline \multicolumn{5}{|l|}{6 mo after first exposures } \\
\hline Fish group & 2 & 2 & 1.73 & 0.367 \\
\hline Odour & 1 & 2 & 25.22 & $0.037^{*}$ \\
\hline Fish group and odour & 2 & 2 & 0.11 & 0.903 \\
\hline${ }^{*}$ Significant difference & & & & \\
\hline
\end{tabular}

\section{DISCUSSION}

\section{Effect of food distribution}

Until the start of the experiment the naïve gobies were only fed pellets, which were evenly distributed on the water surface of the tanks. When food was presented at the 2 feeding sites, the naïve gobies responded immediately by distributing themselves according to the food (Ideal Free Distribution, Fretwell \& Lucas 1970; Input Match, Parker 1978), in agreement with earlier findings on wild two-spotted gobies (Utne et al. 1993). The naïve gobies sampled the 2 food patches for a few min before reaching an IFD, in a scenario similar to that previously observed in wild twospotted gobies (Utne et al. 1993). Thus, patch sampling and learning of food distribution seem to be important in evolutionary terms.

\section{Visual and chemical predator stimuli}

Even though the cod visual stimulus had a lower avoidance effect on naïve compared to wild gobies, there was also a significant avoidance effect in the naïve gobies. Thus, two-spotted gobies appear to display an inherited avoidance response to visual cod stimuli, or at least to visual stimuli of a larger fish. The latter explanation is more likely, given that in the twospotted gobys' natural habitat most larger fish, with the exception of the Labridae, are potential predators.
Since failing to identify a predator may lead to death, while failing to identify a non-predator may only mean a loss of foraging opportunity (the 'death versus dinner' dilemma), fish should initially fear all large unfamiliar animals.

In a study of visual cues for predator face recognition, Karplus (1981, 1982) showed that typical piscivorous face cues (broad head, long distance between eyes, and large mouth) creates an anti-predator response in Chromis caeruleus (a small schooling reef fish), while non-piscivorous face cues (narrow head and small mouth) do not. Cod has the face cues of a piscivore, while the Labridae have the cues of a none piscivore. In the future it would be interesting to investigate the response of naïve and wild gobies facing the visual cues of a larger Labridae, in order to see whether face cues are important for the two-spotted goby, and whether the response is inherited.

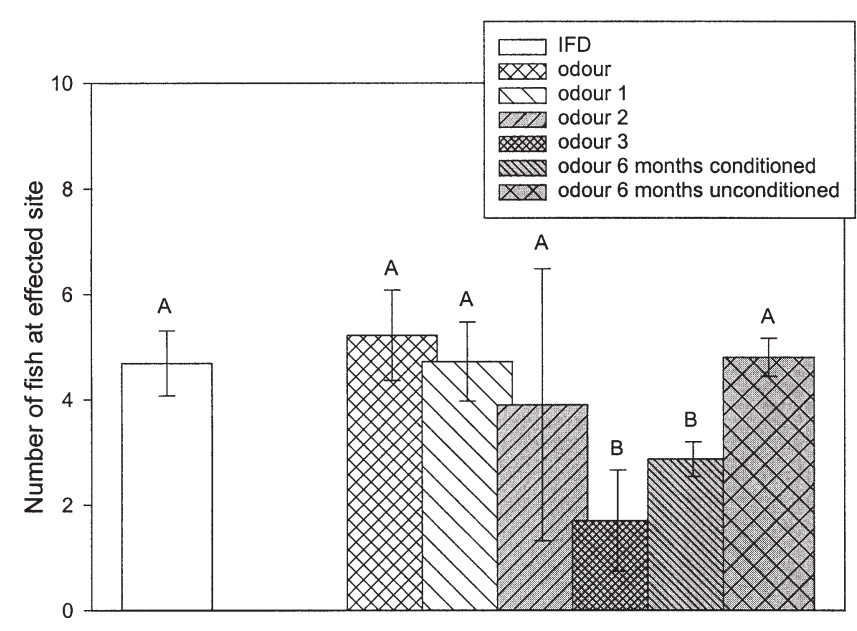

Fig. 2. Effect of learning on naïve Gobiusculus flavescens anti-predator response. Average number of G. flavescens on affected feeding side of aquarium when stimulus introduced. Standard errors indicated. Significant relations between treatments indicated (A \& B) on top of bar. IFD: Ideal Free Distribution, when only food presented; Odour: mean number of fish (mnf) at side where predator odour presented; Odour 1, odour 2 or odour 3 : mnf at side where predator odour presented the day after a cod had been physically present in the aquarium for 20 min on 1 occasion (odour 1 ) or on 2 (odour 2 ) or 3 (odour 3) subsequent days; Odour 6 mo conditioned: mnf at side where predator odour presented, 6 mo after codconditioning treatment; Odour 6 mo unconditioned: mean number of unconditioned fish at the side where predator odour presented, 6 mo after first test for response to cod odour 
Table 3. Two-way ANOVA for repeated measurements with Newman-Keults post hoc test expressing significance level (p) of differences between the different stimuli treatments (glass container, cod image, cod odour, cod physically present, odour when confronted with cod 3 times and odour 6 mo after the third cod confrontation) (Fig. 2)

\begin{tabular}{|c|c|c|c|c|c|c|}
\hline Average no. of fish at affected site: & $\begin{array}{c}\text { Glass } \\
\text { container } \\
(4.95)\end{array}$ & $\begin{array}{l}\text { Image } \\
(0.46)\end{array}$ & $\begin{array}{l}\text { Odour } \\
(5.41)\end{array}$ & $\begin{array}{c}\text { Cod } \\
\text { present } \\
(0.26)\end{array}$ & $\begin{array}{c}\text { Odour after } 3 \\
\text { confrontations } \\
(1.75)\end{array}$ & $\begin{array}{c}\text { Odour } \\
6 \text { mo later } \\
(2.84)\end{array}$ \\
\hline Food only (IFD) & 0.8703 & $0.0001^{*}$ & 0.4108 & $0.0002^{*}$ & $0.0002^{*}$ & $0.0012^{*}$ \\
\hline Image & - & - & $0.0002^{*}$ & 0.6567 & $0.0073^{*}$ & $0.0003^{*}$ \\
\hline Odour & - & - & - & $0.0002^{*}$ & $0.0002^{*}$ & $0.0003^{*}$ \\
\hline Cod present & - & - & - & - & $0.0074^{*}$ & $0.0002^{*}$ \\
\hline Odour after 3 confrontations & - & - & - & - & - & $0.0207^{*}$ \\
\hline
\end{tabular}

The naïve gobies' avoidance of the visual stimulus site did not persist on the following day, as was the case in wild gobies (Utne \& Bacchi 1997)(Fig. 1). Even the 'cod-conditioned' gobies did not avoid the previous day's visual image site on the following day. It is possible that naïve cod-conditioned gobies are more fearless, as they have had limited experience of cod as a stationary predator (Svåsand 1990). Earlier studies have shown that predator-naïve fish are more riskprone than wild fish (Johnsson et al. 1996), and that prey learn to use different anti-predator behaviours/ strategies for different predators (e.g. Lima \& Dill 1990, Lima 1992, Sih et al. 1998). The latter is probably a result of experience and of plasticity in anti-predator behaviour.

The avoidance effect was significantly stronger in the visual stimulus or actual cod trials than in the odour experiments with conditioned fish (Table 3, Fig. 1). In an earlier study of wild two-spotted goby (Utne \& Bacchi 1997) the same relationship between image and odour was found. The cause of this difference was probably that in the experiment with odour alone, the gobies had to visit the affected feeding site to sense the predator, while in the visual stimulus trials they could see the predator from a distance. The number of fish at the chemically affected site was therefore higher in the experiments without visual cues.

There was a higher frequency of inspection in this study of naïve gobies (0.8) than in the earlier study of wild gobies $(0.7)$, and the mean inspection time (i.e. time used on the predator side looking at the predator) was longer in naïve (2.0 min) than wild gobies (0.8 min) (Utne \& Bacchi 1997). The higher inspection rate and longer inspection time might explain why more individuals were present at the cod visual stimulus site in the study of naïve gobies than the study of wild gobies. Since the naïve gobies had never seen a cod before, and therefore had no basis for comparison, higher inspection rates and longer inspection times were to be expected. Magurran \& Seghers (1994) found that min- nows from areas of low predation pressure showed higher levels of predator inspection behaviour. However, it is difficult to distinguish between general curiosity and predator inspection behaviour, and it is generally accepted that predator inspection behaviour has a large curiosity component (Godin \& Crossman 1994). In a heterogeneous habitat, with frequent changes in food availability and habitat structure, it may well pay to sample novel objects in the hope of uncovering and exploiting new resources.

This study found a higher inspection rate in the visual stimulus trials than those in which a cod was actually present in the aquarium. When the cod was introduced into the aquarium, its aggressive and attack behaviour chased the gobies out of the area into the safe side of the aquarium. However, once they had been chased out many of them lined up just outside the net to look at (i.e. inspect) the cod from the safe side of the tank.

\section{Time and learning}

The naïve gobies responded significantly to both visual stimuli and the presence of a cod, while they needed to have experienced an actual cod before responding to cod odour. In sticklebacks Gasterosteus aculeatus (Benzie 1965) and minnows Phoxinus phoxinus (Magurran 1990) various aspects of predator avoidance are significantly enhanced in fish that have been exposed to predatory attacks (Huntingford \& Write 1992). Similarly, coho salmon smolts Oncorhynchus kisutch that had experienced 2 short periods of attacks by piscivorous fish were subsequently more effective at surviving real attacks than naïve smolts (Olla \& Davis 1989). This suggests that the current population of two-spotted gobies is a result of selection by predation, but that individual experience is needed for recognition of the chemical stimuli of a given predator.

In a field situation a naïve goby will probably be able to escape a predator cod if it detects it visually in time 
to escape. Turbidity is often high in the littoral zone due to runoff from land, and G. flavescens have relatively poor light sensitivity (Utne 1997). Cod use olfaction to search for prey, which enables them to hunt when visibility is poor (Brawn 1969), i.e. at night and during twilight (Blegvad 1917), and in high turbidity. Thus, a naïve goby that has not learned to recognise cod odour would have a reduced chance of escaping under poor visual conditions. It is possible that the twospotted goby, like the paradise fish Macropodus opercularis (Csányi 1985), has the ability to learn which species are dangerous and to continue to avoid them while it habituates to species that do not attack. To clarify this possibility, parallel studies on naïve gobies with a non-predatory larger fish (e.g. a Labridae species) are needed.

In this study the naïve gobies needed 3 trials of 20 min exposure to a live cod, in order for a significant avoidance response to cod odour to be elicited. However, there were differences between the groups in that some responded after only a second exposure. This variation could be a result of the predator behaving in a more or less threatening way in the different replicates. This is one of the drawbacks of using a live predator instead of a model predator, whose behaviour can be controlled to be exactly the same in each replicate.

A study of naïve fathead minnows Pimephales promelas found no fright response to visual or chemical cues of pike Esox lucius, but a fright response to pike odour was found 2 to $4 \mathrm{~d}$ after pike had been stocked in the pond (Brown et al. 1997). Brown \& Warburton (1999) showed that naïve rainbowfish Melanotaenia duboulayi learned to avoid a predator (in this case a trawl net) after 3 to 5 exposures. Olla \& Davis (1989) showed that naïve juvenile hatchery-reared coho salmon Oncorhynchus kisutch were better able to avoid capture by a predator after exposure to stimuli associated with predation for two 15 min bouts.

The gobies' learning ability might change during life, as studies have shown that some species of fish are better learners at a certain age (Winberg \& Olsén 1992, Masuda \& Ziermann 2000). The gobies used in this study were adults, while the 2 above-mentioned studies have shown that learning is highest early in life (Winberg \& Olsén 1992), or at a specific juvenile stage (Masuda \& Ziermann 2000). Less training might have been necessary if the gobies had been exposed to the live cod at an earlier age.

In this study, naïve gobies responded significantly to predator odour 6 mo after the conditioning trials. Similarly, fathead minnows Pimephales promelas that had been stimulated with alarm substance and a visual stimulus of a pike Esox lucius still responded significantly to visual stimuli of pike 2 mo later (Chivers \&
Smith 1994). Paradise fish Macropodus opercularis exposed to goldfish Carassius auratus for only $5 \mathrm{~min}$ recognised them after 3 mo (Csányi et al. 1989). Considering that the two-spotted goby lives for only 1 to $2 \mathrm{yr}, 6$ mo could be regarded as permanent memory. Although we do not know whether the learned response in our study is really permanent, in nature the gobies will have the opportunity of continual reinforcement as they are probably frequently exposed (i.e. more often than every 6 mo) to cod odour in association with predator attacks.

Acknowledgements. I am grateful to Hege Folkestad for providing me with Gobiusculus flavescens larvae, and to Sari S. K. Arias for assisting with larvae maintenance. I also thank Anne Gro V. Salvanes for lending me a cod and for her valuable suggestions for improvements to the manuscript. I further wish to thank the Department of Fisheries and Marine Biology, University of Bergen for providing the facilities.

\section{LITERATURE CITED}

Abrahams MV, Dill LM (1989) A determination of the energetic equivalence of risk of predation. Ecology 70: 999-1007

Benzie VL (1965) Some aspects of the anti-predator responses of two species of sticklebacks. PhD thesis, University of Oxford

Blegvad H (1917) On the food of fish in Danish waters within the Skaw. Rep Dan Biol Sta 24:19-72

Brawn VM (1969) Feeding behaviour of cod (Gadus morhua). J Fish Res Board Can 26:583-596

Brown C, Warburton K (1999) Differences in timidity and escape responses between predator-naïve and predatorsympatric rainbowfish populations. Ethology 105:491-502

Brown GE, Chivers DP, Smith RJF (1997) Differential learning rates in chemical versus visual cues of a northern pike by fathead minnows in a natural habitat. Environ Biol Fishes 49:89-96

Chivers DP, Smith RJF (1994) Fathead minnows, Pimphales promelas, acquire predator recognition when alarm substance is associated with the sight of unfamiliar fish. Anim Behav 48:597-604

Csányi V (1985) Ethological analysis of predator avoidance by the Paradise fish (Macropodus opercularis L.). I. Recognition and learning of predators. Behaviour 92:227-240

Csányi V, Dóka A (1993) Learning interaction between prey and predator fish. Mar Behav Phys XXIII: 69-78

Csányi V, Csizmadia G, Miklósi Å (1989) Long-term memory and recognition of another species in the paradise fish. Anim Behav 37:908-911

Dill MD (1974) The escape response of the zebra danio (Brachydanio rerio) II. The effect of experience. Anim Behav 22:723-730

Fretwell SD, Lucas HL (1970) On territorial behaviour and other factors influencing habitat distribution in birds. 1. Theoretical development. Acta Biotheor 19:16-36

Giles N (1984) Development of overhead fright response in wild and predator-naïve three-spined sticklebacks Gasterosteus aculeatus L. Anim Behav 32:276-279

Gillis DM, Kramer DL (1987) Ideal interference distributions: population density and patch use by zebrafish. Anim Behav 35:1875-1882 
Godin JGJ, Crossman SL (1994) Hunger-dependent predator inspection and foraging behaviour in the three-spined stickleback (Gasterosteus aculatus) under predation risk. Behav Ecol Sociobiol 34:359-366

Hirvonen H, Ranta E, Piironen J, Laurila A, Peuhkuri N (2000) Behavioural responses of naïve Arctic charr young to chemical cues from salmonid and non-salmonid fish. Oikos 88:191-199

Huntingford FA, Write PJ (1992) The development of adaptive variation in predator avoidance in freshwater fishes. In: Huntingford FA, Torricelli P (eds) Behavioural ecology of fishes. Harwood Academic Publishers, Switzerland, p 45-61

Johnsson JI, Petersson E, Jönsson E, Björnsson BTH, Järvi T (1996) Domestication and growth hormone alter antipredator behaviour and growth patterns in juvenile brown trout, Salmo trutta. Can J Fish Aqua Sci 53:1546-1554

Karpulus I, Algom D (1981) Visual cues for predator face recognition by reef fishes. Z Tierpsychol 55:343-364

Karpulus I, Goren M, Algom D (1982) A preliminary experimental analysis of predator face recognition by Chromis caeruleus (Pisces, Pomacentridae). Z Tierpsychol 58: $53-65$

Lima SL (1992) Life in a multi-predator environment: some considerations for anti-predator vigilance. Ann Zool Fenn 29:217-226

Lima SL, Dill LM (1990) Behavioural decision made under risk of predation: a review and prospectus. Can J Zool 68: 619-640

Magurran AE (1990) The inheritance and development of minnow anti-predator behaviour. Anim Behav 39:834-842

Magurran AE, Segers BH (1994) Predator inspection behaviour covaries with schooling tendency amongst wild guppy, Poecilia reticulata, populations in Trinidad. Behaviour 128:121-134

Masuda R, Ziemann DA (2000) Ontogenetic changes of learning capability and stress recovery in Pacific threadfin juveniles. J Fish Biol. 56:1239-1247

Milinski M (1979) An evolutionary stable feeding strategy in sticklebacks. Z Tierpsych 51:36-40

Nordeide JT, Salvanes AGV (1991) Observations on reared newly released and wild cod (Gadus morhua) and their potential predators. ICES Mar Sci Symposia 192:139-146

Olla BL, Davis MW (1989) The role of learning and stress in predator avoidance of hatchery-reared coho salmon (Oncorhynchus kisutch) juveniles. Aquaculture 76: 209-214

Editorial responsibility: Otto Kinne (Editor), Oldendorf/Luhe, Germany
Parker GA (1978) Searching for mates. In: Krebs JR, Davies NB (eds) Behavioural Ecology, 1st edn. Blackwell Scientific Publications, Oxford p 214-244

Pfeiffer W (1977) The distribution of fright reaction and alarm substance cells in fishes. Copeia 1977:653-665

Pitcher TJ, Green DA, Magurran AE (1986) Dicing with death: predator inspection behaviour in minnows shoals. J Fish Biol 28:439-448

Pitcher TJ, Lang SH, Turner JR (1988) A risk-balancing tradeoff between foraging rewards and predation risk in shoaling fish. Behav Ecol Sociobiol 22:225-228

Sih A, Englund G, Wooster D (1998) Emergent impact of multiple predators on prey. Trends ecol Evol 13:350-355

Skolbekken R, Utne-Palm AC (2001) Parental investment of male two-spotted goby Gobiusculus flavescens (Fabricius). J Exp Mar Biol Ecol 261:137-157

Smith RJF (1989) The response of Asteropteryx semipunctatus and Gnatholepis anjerensis (Pisces, Gobiidae) to the chemical stimuli from injured conspecifics, an alarm response in gobies. Ethology 81:279-290

Suboski MD (1990) Releaser-induced recognition learning. Psychol Rev 97:271-284

Svåsand T (1990) Comparisons of migration patterns of wild and recaptured reared coastal cod, Gadus morhua L., released in a small fjord in western Norway. Aqua Fish Manag 21:491-495

Utne ACW (1995) Experimental investigation of habitat choice of fish. PhD thesis, University of Bergen

Utne ACW (1997) The effect of turbidity and illumination on the reaction distance and search time of a marine planktivore (Gobiusculus flavescens). J Fish Biol 50:926-938

Utne ACW, Aksnes DL (1994) An experimental study on the influence of feeding versus predation risk in the habitat choice of juvenile and adult two-spotted goby Gobiusculus flavescens (Fabricius). J Exp Mar Biol Ecol 179:69-79

Utne ACW, Bacchi B (1997) The influence of visual and chemical stimuli from cod (Gadus morhua) on the distribution of two-spotted goby Gobiusculus flavescens (Fabricius). Sarsia 82:129-135

Utne ACW, Aksnes DL, Giske J (1993) Food, predation-risk and shelter: an experimental study on the distribution of adult Gobiusculus flavescens. J Exp Mar Biol Ecol 166: 203-216

Winberg S, Olsén HK (1992) The influence of rearing conditions on the sibling odour preference of juvenile Arctic charr, Salvelinus alpinus L. Anim Behav 44:157-164

Submitted: April 4, 2001; Accepted: June 26, 2001

Proofs received from author(s): July 31, 2001 